\title{
Effects of ethyl alcohol on sphincteric resistance at the choledocho-duodenal junction in man
}

\author{
R. C. PIROLA AND A. E. DAVIS \\ From the Division of Gastroenterology, School of Medicine, \\ University of N.S.W., Sydney, Australia
}

The association between alcoholism and pancreatic disease is well recognized (Joske, 1955; Richman, 1956; Bennett and Jepson, 1966), but despite a considerable amount of animal experimental work the nature of this association remains uncertain. The majority of experiments have been performed on different species of animals whose pancreaticobiliary systems vary anatomically and functionally from that of the human (Boyden, 1957; Mann, 1920). A widely held theory is that alcohol causes a duodenitis which in turn causes pancreatic duct obstruction. At the same time the pancreas is stimulated as a result of increased gastric acid production and release of secretin. It is postulated, therefore, that the combination of pancreatic duct obstruction and pancreatic stimulation leads to ductular rupture and pancreatitis (Dreiling, Richman, and Fradkin, 1952).

In a recent study on normal volunteers, it was demonstrated that the height of the blood alcohol was more important than the route of administration in producing obstruction to pancreatic outflow (Davis and Pirola, 1966). Pressure studies in the pancreatico-biliary system were not performed. The following studies were designed first to investigate the action of intravenous alcohol on the outflow resistance of the sphincter of Oddi and secondly to re-examine the widely held view that alcohol causes a duodenitis and hence obstruction of the pancreatic duct.

\section{MATERIALS AND METHODS}

COMMON BILE DUCT PRESSURES Ten patients were studied. Each had a choledochotomy tube present following a cholecystectomy and choledochotomy performed two to 14 days previously. The patients were fasting and had received no medication for at least 24 hours before the test. In seven subjects, the common bile duct pressures were measured by means of a manometer containing normal saline. The reference point was taken as midway between anterior and posterior abdominal walls. In three subjects, pressures were recorded with an Offner
R S dynograph strain gauge manometer. In this group, normal saline was injected by a constant infusion pump through a $\mathrm{Y}$ connexion into the choledochotomy tube at a rate of $300 \mathrm{ml} / \mathrm{hr}$ for 30 seconds every five minutes.

In all subjects, after an observation period of 20 minutes, alcohol was given intravenously as a $10 \%$ solution in $5 \%$ glucose over 20 minutes. Total alcohol infused was $600 \mathrm{mg} / \mathrm{kg}$ body weight except subjects 7 and 9 who received $900 \mathrm{mg} / \mathrm{kg}$ and $300 \mathrm{mg} / \mathrm{kg}$ respectively. In addition, subject 10 received a further dose of 450 $\mathrm{mg} / \mathrm{kg} 20$ minutes after the end of the first infusion. Each subject, except one, was tested on a separate occasion with 10 to $15 \mathrm{mg}$ parenteral morphine.

ALCOHOL AND DUODENITIS Five patients were studied. All were chronic alcoholics admitted to hospital during a drinking spree and in the weeks before admission had been consuming an average of $600 \mathrm{~g}$ of alcohol per man per day. A typical case history was that of patient number 4 who in the six weeks before admission had drunk 2 measures of rum, $220 \mathrm{oz}$ beer, and one bottle of port per day. Intestinal biopsies were obtained by a Crosby capsule (Crosby and Kugler, 1957) under fluoroscopic control from the second part of the duodenum within 15 hours of admission into hospital. The marked nausea that is typical of severe alcoholism makes duodenal intubation a difficult procedure in these patients. Before the test, each subject was therefore given $20 \mathrm{mg}$ intramuscular metoclopramide, an agent recently shown to reduce delay at the pylorus (Pirola, 1967). Duodenal mucosal specimens were examined under the dissecting microscope and the light microscope.

\section{RESULTS}

COMMON BILE DUCT PRESSURES The effects of intravenous alcohol and morphine on common bile duct pressures are shown in Table I. In the saline manometer studies with alcohol, the mean pressure in the common bile duct in the control period was $13.2 \mathrm{~cm}$ normal saline (range 7.5 to $17 \mathrm{~cm}$ ) and rose by an average of $4.4 \mathrm{~cm}$ (range 0 to $9 \mathrm{~cm}$ ). In the tests using morphine, the mean basal pressure was $11.9 \mathrm{~cm}$ normal saline (range 11.5 to $14.5 \mathrm{~cm}$ ) and rose by an average of $7 \cdot 6 \mathrm{~cm}$ (range 0 to $16 \mathrm{~cm}$ ). 
TABLE I

EFFECT OF INTRAVENOUS ALCOHOL AND MORPHINE ON COMMON BILE DUCT PRESSURES ${ }^{1}$

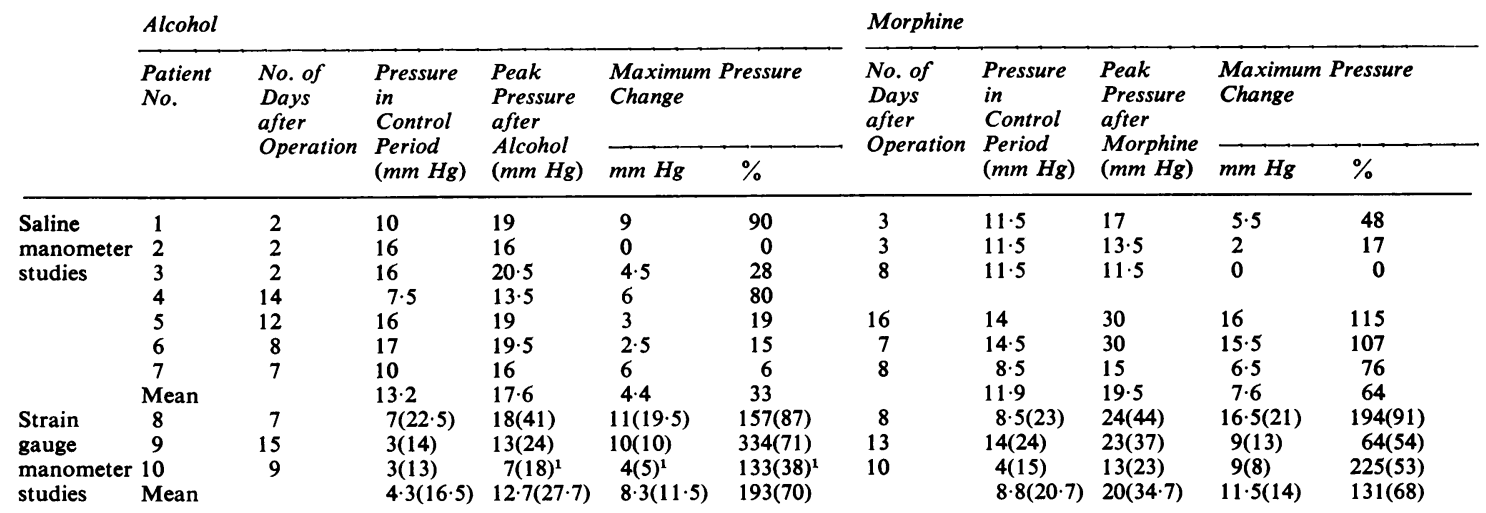

${ }^{1}$ Pressures recorded after initial dose of alcohol $(600 \mathrm{mg} / \mathrm{kg})$

These results are shown diagrammatically in Figure 1.

In the three studies using a strain gauge manometer, mean pressures with and without infusion of the common bile duct showed rises after alcohol of $8.3 \mathrm{~mm} \mathrm{Hg}$ and $11.5 \mathrm{~mm} \mathrm{Hg}$ respectively. The corresponding mean rises in pressure in studies using morphine were $11.5 \mathrm{~mm} \mathrm{Hg}$ and $14 \mathrm{~mm} \mathrm{Hg}$. In subject 10 , the second dose of alcohol resulted in further rises in pressure of $6 \mathrm{~mm} \mathrm{Hg}$ without ductal infusion and $7 \mathrm{~mm} \mathrm{Hg}$ during ductal infusion. In each subject, the inhalation of amyl nitrite caused a sharp fall in the elevated pressures that followed alcohol and morphine. The results obtained in a typical experiment are shown in Figure 2. Two subjects (9 and 10) were tested separately with $500 \mathrm{ml} 5 \%$ glucose intravenously, in each case without rise in pressure.

In all subjects the rise in pressure after alcohol started five to 10 minutes after the start of the infusion and reached a peak at the end of the infusion.

DUODENAL BIOPSIES IN ALCOHOLIC SUBJECTS The appearances of the duodenal mucosa from each of the five alcoholic subjects were normal under both the dissecting microscope and the light microscope. Typical examples are shown in Figures 3 and 4. No evidence of duodenitis was found.

\section{DISCUSSION}

These investigations show that intravenous alcohol

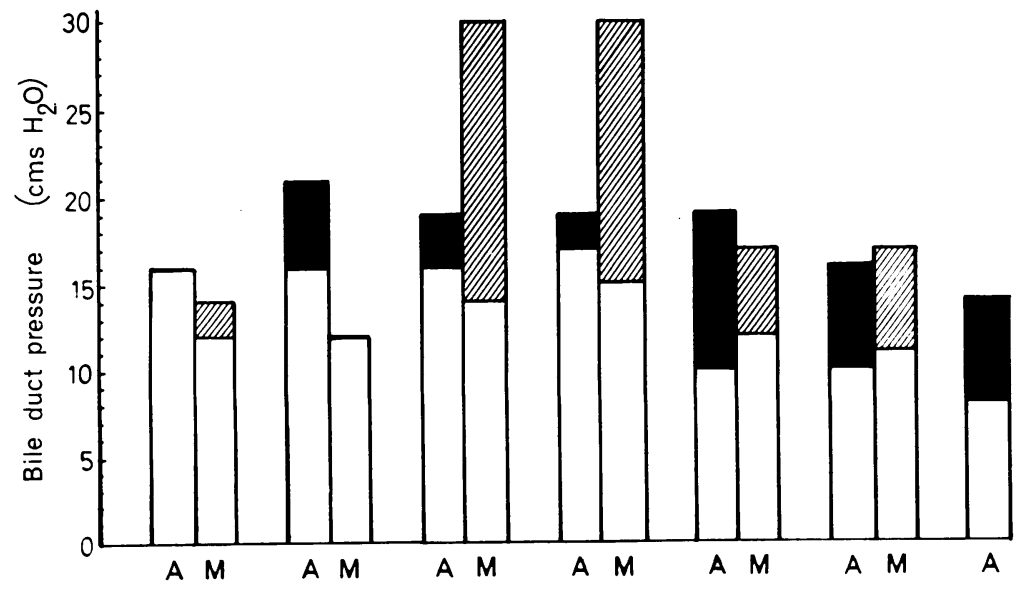

FIG. 1. The results of estimations of common bile duct pressures by means of a saline manometer in seven patients. Each pair of blocks represents a separate patient. The height of the clear area in each block shows the mean pressure in a 20-minute observation period. The peak rises in pressure after alcohol $(A)$ or morphine $(M)$ are represented by the black and shaded areas. 


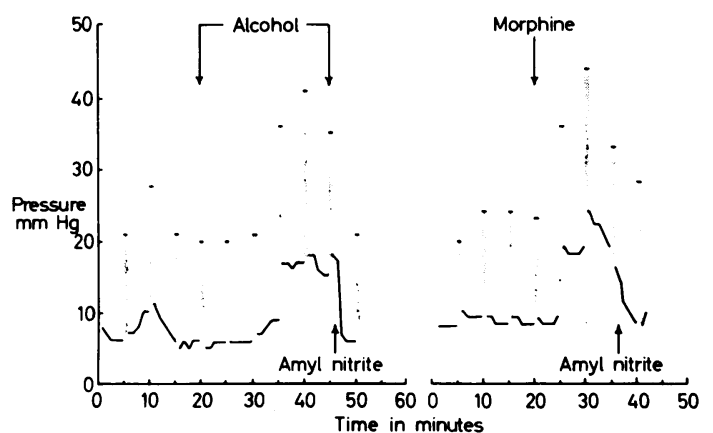

FIG. 2. Common bile duct pressures recorded by means of a strain gauge manometer in one patient. Regular sharp rises and falls in pressure occur when saline is injected into the cholodochotomy tube for 30 seconds every five minutes. Two tests were carried out on separate days; in one, 575 $\mathrm{ml} 10 \%$ alcohol in $5 \%$ dextrose was given intravenously, in the other $10 \mathrm{mg}$ morphine was injected subcutaneously.

causes a rise in common bile duct pressure similar to that obtained with morphine. This rise of pressure could result from increased resistance to flow or from increased rate of flow.

From the pressure curves obtained in tests employing intermittent infusion of the common bile duct (Fig. 2), it would appear that an increased rate of bile flow would have to be of the order of $300 \mathrm{ml} / \mathrm{hr}(7.2$ litres/day) to account for the pressure obtained. This would appear unlikely.

Increased resistance to flow appears to be the more likely mechanism, the site of the resistance being the sphincteric musculature at the choledochoduodenal junction. This is supported by the sharp reduction in pressure after amyl nitrite and the similarity in pressure responses between alcohol and morphine. Resistance to flow would also explain the previous finding of decreased duodenal aspirate volumes after intravenous alcohol (Davis and Pirola, 1966).

The theory that alcohol has a local irritant action resulting in duodenitis has been frequently quoted (Dreiling et al, 1952; Hermann and Davis, 1960; McKay, 1966), but no supporting histological studies have been reported. Each of the duodenal biopsy specimens reported here was obtained from a chronic alcoholic at the end of a drinking spree, yet no evidence of duodenitis was found. The existence of duodenitis as a distinct clinical entity is controversial (Beck, Kahn, Lacerte, Solymar, Callegarini, and Geokas, 1965) and while there is no evidence that it occurs in asssociation with excessive alcohol consumption, there is no doubt that it can occur in association with other conditions (Wechsler, 1964).

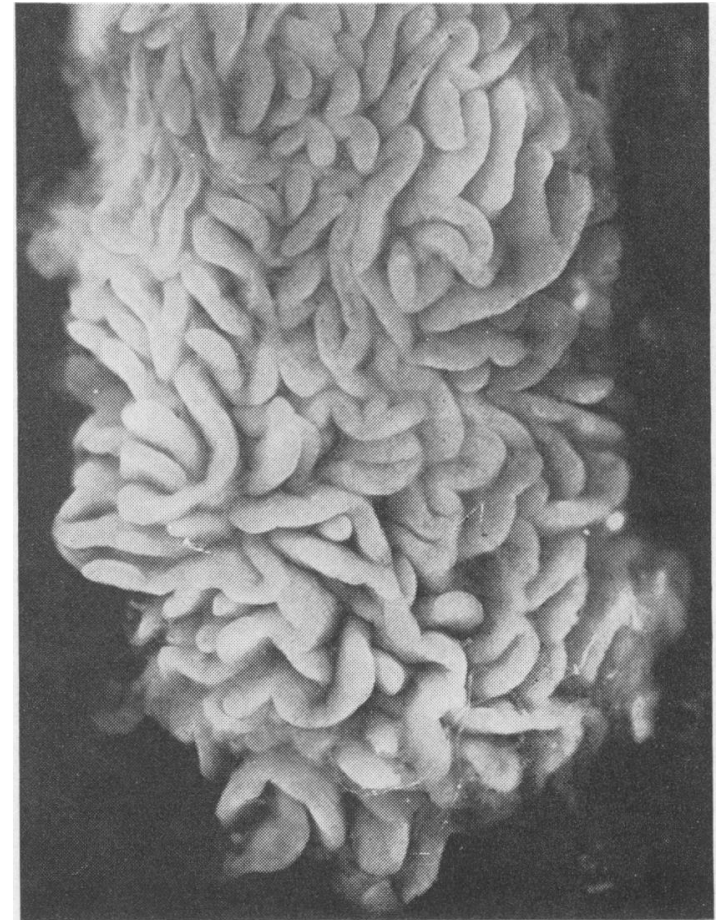

FIG. 3. Photomicrograph of the dissecting microscope appearances of the mucosal surface of the duodenum in subject no. 4. The villi appear quite normal with no tendency to clumping or flattening $(\times 10)$.

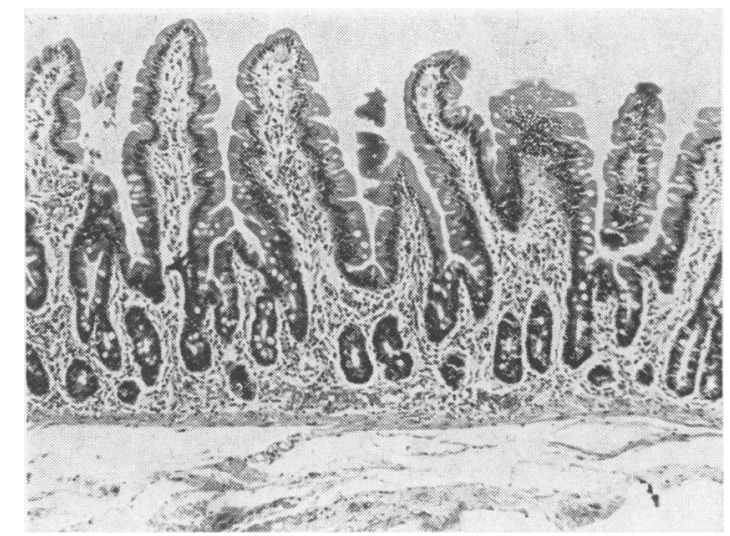

FIG. 4. Photomicrograph of duodenal biopsy of subject no. 4. The appearances are normal (haematoxylin and $\operatorname{eosin} \times 75)$. 
In a previous study (Davis and Pirola, 1966) the effects of intravenous and intraduodenal alcohol on pancreatic exocrine function have been compared. It was found that a greater reduction in the volume of duodenal aspirate was obtained with intravenous alcohol than with intraduodenal alcohol and that this reduction was related to the blood level of alcohol rather than to the route of administration. In view of the increase in pressures in the common bile duct observed with intravenous alcohol and the normal histological appearance of duodenal biopsies in alcoholics, this reduction in volume of the duodenal aspirate was more likely the result of increased sphincteric resistance than alcohol-induced duodenitis. It is postulated from these findings that alcohol causes increased tone in the sphincteric mechanism of the choledochoduodenal junction, an effect related to the level of alcohol in the blood. The obstructive effect of alcohol would normally occur at times of pancreatic stimulation by food and alcohol and may be a major factor in alcoholinduced pancreatic disease.

\section{SUMMARY}

The effects of intravenous alcohol in common bile duct pressures in 10 patients were studied. Rises in pressure were similar to those obtained with morphine.

Biopsy specimens of duodenal mucosa from five patients with acute-on-chronic alcoholism were examined and no evidence of duodenitis was found. It is postulated that alcohol causes increased tone in the sphincteric mechanism at the choledocho- duodenal junction and that this effect is related to the level of alcohol in the blood and not to the production of a duodenitis.

We wish to thank Dr B. P. Billington for his advice and enthusiastic support and the staffs of the Prince Henry and Prince of Wales Hospitals who referred the patients. Dr A. G. Liddelow helped in the interpretation of the duodenal biopsies. Metoclopramide was supplied by Merck, Sharp and Dohme International Research.

\section{REFERENCES}

Beck, I. T., Kahn, D. S., Lacerte, M., Solymar, J., Callegarini, U., and Geokas, M. C. (1965). 'Chronic duodenitis': a clinical pathological entity? Gut, 6, 376-383.

Bennett, R. C., and Jepson, R. P. (1966). Acute pancreatitis in South Australia. Med. J. Aust., 1, 126-129.

Boyden, E. A. (1957). The choledochoduodenal junction in the cat. Surgery, 41, 773-786.

Crosby, W. H., and Kugler, H. W. (1957). Intraluminal biopsy of the small intestine. Amer. J. dig. Dis., 2, 236-241.

Davis, A. E., and Pirola, R. C. (1966). The effects of ethyl alcohol on pancreatic exocrine function. Med. J. Aust., 2, 757-760.

Dreiling, D. A., Richman, A., and Fradkin, N. F. (1952). The role of alcohol in the etiology of pancreatitis: a study of the effect of intravenous ethyl alcohol on the external secretion of the pancreas. Gastroenterology, 20, 636-646.

Hermann, R. E., and Davis, J. H. (1960). The role of incomplete pancreatic duct obstruction in the etiology of pancreatitis. Surgery, 48, 318-329.

Joske, R. A. (1955). Aetiological factors in the pancreatitis syndrome. Brit. med. J., 2, 1477-1481.

McKay, I. R. (1966). The effects of alcohol on the gastro-intestinal tract. Med. J. Aust., 2, 372-376.

Mann, F. C. (1920). A comparative study of the sphincter at the duodenal end of the common bile-duct with special reference to species of animals without a gall-bladder. Anat. Rec., 18, 355-360.

Pirola, R. C. (1967). Rapid duodenal intubation with metoclopramide. Amer. J. dig. Dis., 12, 913-915.

Richman, A. (1956). Acute pancreatitis. Amer. J. Med., 21, 246-274.

Wechsler, R. (1964). Duodenitis. Gastroenterology, vol. II, 2nd ed., pp. 119-124, edited by H. L. Bockus. Saunders, London and Philadelphia. 